\title{
Consideraciones médico legales sobre la capacidad de culpabilidad
}

\author{
Frank Harbottle Quirós \\ Universidad de Costa Rica \\ frank.harbottlequiros@ucr.ac.cr
}

Fecha de recibido: octubre 2016 / Fecha de aprobación: mayo 2017

\section{Resumen}

El presente artículo contiene un estudio desde una perspectiva médico legal sobre la capacidad de culpabilidad, concretamente, sobre la imputabilidad, la inimputabilidad y la imputabilidad disminuida. En el primer apartado, estas categorías se analizan dentro del contexto libertad vs determinismo. Luego se conceptualizan a la luz de la teoría del delito. Posteriormente, se exponen las principales causas de exclusión y de disminución de la capacidad de culpabilidad contempladas por diversas legislaciones. Finalmente, se examinan los componentes empírico y normativo y su importancia para la delimitación de las labores del perito y del juez.

\section{Palabras Clave}

Imputabilidad / imputabilidad disminuida/ inimputabilidad / juez / perito

\section{Abstract}

This article contains a study from a forensic perspective on the ability of guilt, specifically, on the criminal liability, diminished criminal liability and non-imputability. In the first section, these categories are analyzed within the context of freedom vs. determinism. Then they conceptualized as integral elements of the theory of crime. Subsequently, the document presents the main causes of exclusion and diminished the ability of guilt established in different laws. Finally, the article analyzes the empirical and normative components and their importance for the delimitation of the work of the expert and the judge.

\footnotetext{
Criminal liability/ diminished criminal liability/ non-imputability / judge / expert
} 


\section{Tabla de contenido}

I. Introducción. 2. Aproximación histórica al tema de la capacidad de culpabilidad: libertad vs determinismo. 3. Conceptualización de la imputabilidad, inimputabilidad e imputabilidad disminuida. 4. Principales causas de exclusión o disminución de la capacidad de culpabilidad.5. Componentes de la capacidad de culpabilidad. 5.I. Empírico: labor del perito. 5.2. Normativo: labor del órgano juzgador. 6. Conclusiones. Bibliografía.

\section{Introducción}

En este artículo se aborda la capacidad de culpabilidad desde una perspectiva médico legal. En un primer apartado, se presentan los antecedentes históricos de la imputabilidad, inimputabilidad e imputabilidad disminuida, partiendo del debate surgido en el siglo XIX sobre el dilema libertad-determinismo. Luego se proceden a conceptualizar estas categorías a la luz de la teoría del delito. Posteriormente, se mencionan las principales causas de exclusión y de disminución de la capacidad de culpabilidad contempladas por diversas legislaciones. Finalmente, se exponen los componentes de la capacidad de culpabilidad con la intención de reflexionar sobre la importancia de estudiar este tema con un enfoque interdisciplinario.

\section{Aproximación histórica al tema de la capacidad de culpabilidad: libertad vs determinismo}

Conforme lo exponen López Miguel y Núñez Gaitán (20I4, p. 88I), tradicionalmente, la enfermedad mental ha sido un factor asociado a la delincuencia. Sin embargo, en la actualidad, no pueden extraerse conclusiones definitivas al relacionarse ambas. No todo criminal o delincuente es un enfermo mental, ni todo enfermo mental comete actos delictivos.

Cuando la "locura" y la "delincuencia" se articulan surge un tema apasionante dentro del campo del derecho penal: la comisión de un hecho delictivo por una persona con un trastorno o anomalía mental. El abordaje de esta temática necesariamente debe hacerse a partir de la categoría dogmática denominada capacidad de culpabilidad o imputabilidad, la cual, en el siglo XIX, generó en Europa una importante discusión-que aún no está acabada a nivel mundial- en cuanto al dilema libertad-determinismo.

Según lo platea el tratadista Muñoz Conde (1988, p. 28), la Escuela Clásica, cuyo mayor representante fue Francesco Carrara, buscó la causa del distinto tratamiento de imputables e inimputables en la tesis del libre arbitrio y la culpabilidad moral, esbozada por Aristóteles, según la cual, el ser humano al utilizar sus facultades intelectivas y volitivas es libre para elegir. En el supuesto de que cometa un delito, usando o abusando de esta libertad es responsable por imputable de este. En cambio, si el sujeto carece de estas facultades se considera que no pude hacer uso de esa libertad y, por lo tanto, no puede ser responsable por inimputable de sus actos.

A criterio de Yáñez Román (1970, p. 307), para el clasicismo penal, la imputabilidad, como primer presupuesto de la pena, era susceptible de medirse cuantitativamente, de ahí que se hablase de imputabilidad agravada y atenuada, completa e incompleta, total y parcial o semi-imputabilidad. 
Con la doctrina clásica, se consideró a la persona normal como totalmente responsable y la completamente anormal totalmente irresponsable, estimándose que quien padecía de un trastorno mental incompleto debía ser responsable sólo de una manera atenuada (Puig Peña, 1955, p. 53).

Así, explica Vela Treviño (1988, p. 296), la enfermedad llegó a verse como manía intelectual (con delirio), manía moral (sin delirio) y manía parcial, limitándose al aspecto morboso o enfermedad, no haciendo extensiva la idea a situaciones que no estén relacionadas con la "locura".

Este planteamiento, basado en el libre arbitrio fue aceptado casi unánimemente y se constituyó en la base teórica de la imputabilidad. Sin embargo, con el progreso científico natural y concretamente de la psiquiatría, a mediados del siglo XIX se empezaron a aplicar métodos de observación científica al crimen para determinar las causas de la criminalidad, dándose el auge de la llamada Escuela Positiva, cuyos mayores representantes fueron Lombroso, Ferri y Garófalo, quienes llegaron a ver al delincuente como un hombre anormal, por sus anomalías orgánicas y psíquicas, hereditarias y adquiridas (Velásquez, I997, pp. 8-9).

De acuerdo con Soler (1989, p. 39), la exposición tradicional del problema de la responsabilidad penal sufrió profundas modificaciones al imponerse en el terreno de la ciencia, incluidas las ciencias biológicas y sociales, una concepción mecanicista. La reducción de las relaciones sociales a una especie de física social y la explicación biológica de los procesos psíquicos, representaron la más radical oposición a una concepción del delito como producto de una voluntad incondicionada y libre. Sobre la base de esa construcción teórica, la escuela positiva italiana trazó un arbitrario clasificatorio de las teorías, llamando con el común denominador de escuela clásica a todo el pensamiento anterior a las nuevas tesis deterministas.

Surge así la escuela positivista italiana como reacción contra el punto de vista clásico. La negación metafísica del principio del libre albedrío, lleva a la afirmación también metafísica del determinismo (Soler, 1989, p. 4I).

Más de ciento cincuenta años después, la idea de la libertad de decisión como rasgo esencial del ser humano es un tema muy discutido en la actualidad en países como Alemania donde está en el centro de una enorme controversia.

Tal y como lo señalan Arocena, Balcarce y Cesano (20I5, Pp. 40-4I), hoy es posible pensar en tres aproximaciones al problema libre albedrío-determinismo. La librealbedrista, según la cual existe una libertad total en la toma de decisiones por parte del individuo. A esta se opone la concepción determinista fuerte, que a su vez afirma que no existe tal cosa como el libre albedrío, pues no se trata más que de una ilusión. Una tercera aproximación, la compatibilista, asume por su parte que libre albedrío y determinismo pueden coexistir.

Bien lo apunta, recientemente, Demetrio Crespo (2015, pp. 39-40), al indicar que el viejo debate sobre determinismo e indeterminismo se ha vuelto extraordinariamente actual a la luz de las últimas investigaciones llevadas a cabo en el campo de la Neurobiología. 
Hoy se ha llegado a descubrir los mecanismos del cerebro que se activan en la toma de decisiones de las personas y cómo las funciones de razonar y decidir pueden ser ubicadas en determinadas regiones cerebrales.

Por ejemplo, en la actualidad se cuenta con investigaciones provenientes de las neurociencias referidas a los daños que puede haber sufrido el agente en los lóbulos frontales y su incidencia en la capacidad de autocontrol (Arocena et al., 2015, p. 103).

Con ello, el debate libertad vs determinismo está más vigente que nunca.

Este panorama abre las puertas al estudio de la capacidad de culpabilidad o imputabilidad, tema sobre el que se expondrá a continuación.

\section{Conceptualización de la imputabilidad, inimputabilidad e imputabilidad disminuida}

En relación con la capacidad mental de una persona para el momento del hecho delictivo es posible pensar en tres escenarios:(i) plena capacidad (imputabilidad); ausencia de capacidad (inimputabilidad) y (iii) capacidad incompleta (imputabilidad disminuida).

La imputabilidad ha sido conceptualizada por Zaffaroni (2002, p. 696) como la ausencia de impedimento de carácter psíquico para la comprensión de la antijuricidad y para la adecuación de la conducta conforme a esa comprensión, es decir, como el conjunto de facultades psíquicas mínimas que debe poseer un sujeto autor de un delito.

De acuerdo con Casanueva Sanz (2013, p. 16), existe cierto consenso en considerar que la imputabilidad se refiere, al menos, a condiciones de carácter psíquico, es decir, al estado de las facultades o capacidades psíquicas del sujeto, las cuales son objeto directo de estudio de ciencias ajenas al Derecho como la Psicología, Psiquiatría, Psicopatología, etc.

En el análisis de la imputabilidad se siguen criterios biológico-psicológicos y psiquiátricos, por cuanto se trata de establecer estados psicopatológicos o anormalidades psíquicas graves (enfermedad mental) de carácter orgánico o de base biológica. Pero, también, se determina la existencia de trastornos, cuya causa no es orgánica o cuya base no es biológica o corporal, denominados trastornos de la conciencia (Chan Mora, 2012, p. 55).

Conforme lo apunta Saborío (2005, pp. 4l-63), el constructo de imputabilidad es un constructo legal que difiere significativamente de constructos psicológicos como inteligencia, psicopatología o personalidad. Las mediciones de constructos psicológicos no se traducen, directamente, en constructos legales, lo cual podría conducir a conclusiones inválidas. Tal es el caso de una persona que puede presentar síntomas suficientes como para ser diagnosticada con un trastorno mental severo (por ejemplo, esquizofrenia) y al mismo tiempo cumplir con criterios suficientes como para considerar que comprende el carácter ilícito de su comportamiento delictivo en el momento de este, lo cual podría llevar a una autoridad judicial a considerarlo imputable (constructo legal). De esta forma, no es posible establecer asociaciones mecánicas directas entre constructos de naturalezas tan diversas como los psicológicos y los legales. Lo que sí debe garantizarse es que los constructos psicológicos evaluados en una persona tengan cierta relevancia en el apoyo a la toma de decisiones sobre constructos legales. 
En la legislación costarricense - tal como sucede en la mayoría de países de tradición jurídica continentalse ha optado por realizar una definición negativa del concepto de imputabilidad: será imputable, quien no se encuentre en algún supuesto de inimputabilidad. Por ello, la imputabilidad se ha concebido como aquello que existe cuando no se presenta una enfermedad mental o un grave trastorno de la conciencia que afectan la capacidad de comprensión y de acción de un sujeto adulto. Se parte de la presunción de que en la vida en sociedad este estado de normalidad psíquica existe, adoptándose una presunción legal iuris tantum, es decir, que admite prueba en contrario (Poder Judicial de Costa Rica, 20 I0, Sala Tercera, Sentencia 2010-00957).

Para que pueda hablarse de inimputabilidad se exige que el sujeto, en su comportamiento antijurídico, sea incapaz de comprender el significado injusto del hecho que realiza (vertiente cognoscitiva) y de dirigir su actuación conforme con dicha comprensión (vertiente volitiva).

Partiendo de lo expuesto por Lin Ching (2002, p. 70), en la capacidad cognitiva se incluyen todas las aptitudes con que el sujeto cuenta para incorporar la información que el medio emite, como lo son los procesos sensoperceptivos y la capacidad intelectual del sujeto. Aquí, se determina si el individuo posee conciencia del carácter ilícito y de las consecuencias de su conducta. Por su parte, la capacidad volitiva comprende todos los aspectos motivacionales que subyacen la conducta de un individuo, las reacciones de ajuste ante las exigencias del medio, la posibilidad real del individuo para actuar conforme con lo que el ordenamiento jurídico espera de él.

La imputabilidad, no se reduce al análisis de la capacidad para comprender la ilicitud del hecho, sino que exige también que el individuo pueda actuar conforme a esa comprensión. Esta capacidad se identifica habitualmente con la voluntad o capacidad volitiva, sin embargo, actualmente se utilizan en su lugar expresiones como capacidad de determinación o autodeterminación, de autoconducción, autocontrol, de autogobernarse o de controlar los impulsos (Casanueva Sanz, 20I3, pp. 40-4I).

En cuanto a la culpabilidad disminuida, autores como Roxin (1997, p. 839) han planteado que no se trata de una forma autónoma de "semiimputabilidad", sino un caso de imputabilidad, pues el sujeto aún es capaz de comprender el injusto del hecho y de actuar conforme con esa comprensión.

Por su parte, para Cabello (1981, p. 187), el término semialienación es vago e impreciso; conlleva al riesgo médico forense de que se convierta en el gran recipiente de las dudas diagnósticas, pasando a ser el comodín de la incertidumbre y la fácil solución jurídica de todos aquellos casos lindantes entre la culpabilidad y la peligrosidad. Similar criterio al de Zazzali (20I5, p. 54), para quien una persona no puede ser medio insana o medio loca, siendo impropio calificar a un sujeto como semi-alienado.

La imputabilidad disminuida es un término muy controvertido. Prueba de ello es que en la actualidad las legislaciones de los países ofrecen distintas respuestas penales para los supuestos en que se demuestra que una persona adulta cometió un hecho sancionado como delito, actuando bajo un estado de imputabilidad disminuida. Por ejemplo, en países como Alemania y Chile se contempla la imposición de una pena de prisión atenuada; en el caso de Costa Rica se dispone la imposición de medidas de seguridad al igual que ocurre con la inimputabilidad y en otros países como España se establece la posibilidad de imponer tanto pena de prisión como medida de seguridad en el orden señalado por el Tribunal. 
Habiendo conceptualizado la imputabilidad, la inimputabilidad y la imputabilidad disminuida, se procede con el estudio de las principales causas que pueden excluir o disminuir la capacidad de culpabilidad.

\section{Principales causas de exclusión o disminución de la capacidad de culpabilidad}

En primer lugar, debe apuntarse que, tal y como lo señalan Arocena et al. (2015, p. 103), no hay que sucumbir a la tentación de convertir las causas de inimputabilidad en "tipos legales" en los que se subsume la situación fáctica que afecta a la inimputabilidad (su presupuesto empírico-biológico).

La descripción legal, taxativa, de las posibles causas de inimputabilidad puede generar dificultades en la medida en que se apoye en clasificaciones psiquiátricas superadas, ello en razón de que la medicina está en constante cambio.

En Costa Rica, cuando se determina en un proceso penal que una persona cometió un delito (conducta típica, antijurídica y culpable), es posible imponerle una pena de prisión. Si dentro del análisis de la culpabilidad se determina que era inimputable, es decir, que al momento de los hechos delictivos la persona no tenía plena capacidad de comprender el carácter ilícito de los hechos o de adecuarse a esa comprensión (Código Penal de Costa Rica, 2015, Art. 42) o que actuó bajo un estado de imputabilidad disminuida, al ser incompleta esa capacidad (Código Penal, numeral 43) resulta improcedente sancionarla con una pena y se le puede imponer una medida de seguridad como el internamiento en un centro psiquiátrico o el sometimiento a un tratamiento ambulatorio (Código Procesal Penal de Costa Rica, 20I3, numerales 98 y $10 \mathrm{I})$, lo anterior, en el tanto se cuente con un pronóstico que, probablemente, en el futuro va a delinquir por ser "peligroso" (Código Penal, ordinal 97).

En la praxis judicial suele aceptarse una fórmula trimembre, incluyéndose, dentro de ella, los trastornos psíquicos que afectan el aspecto intelectual o emocional (enfermedad o causa somática), las oligofrenias, deficiencias o retardos mentales y las anomalías psíquicas que implican una grave perturbación de la conciencia, debida, en la mayoría de los casos, a los efectos del licor y de las drogas.

En España, el Código Penal (20I5, Art. 20, inciso I) establece que está exento de responsabilidad penal el que al tiempo de cometer la infracción, a causa de cualquier anomalía o alteración psíquica, no pueda comprender la ilicitud del hecho o actuar conforme a esa comprensión. A su vez, el numeral 2 I inciso I regula como una circunstancia atenuante, las causas anteriores cuando no concurrieren todos los requisitos necesarios para eximir de responsabilidad en sus respectivos casos.

Conforme lo exponen Corcoy Bidasolo y Mir Puig (20I5, p. II0), el presupuesto psiquiátrico de la fórmula consiste en la actualidad en una "anomalía o alteración psíquica" no transitoria, siendo que, la regulación anterior refería al "enajenado", por lo que sólo alcanzaba al "alienado", lo cual podía resultar adecuado para expresar las enfermedades mentales en sentido estricto, es decir, las psicosis, pero no encuadraba en absoluto a las oligofrenias, que se caracterizan por suponer sólo un grado de inteligencia inferior al normal. No obstante, tanto la doctrina como la jurisprudencia admitieron unánimemente que las oligofrenias profundas merecían la exención de la responsabilidad penal y las incluyeron en el mencionado término "enajenado". Este problema, apuntan, lo resuelve el actual artículo 20 inciso I) de Código Penal español al incluir la expresión "anomalía psíquica” (dentro de las que se pueden ubicar las oligofrenias profundas) junto a la de "alteración psíquica” (enfermedades mentales u otras perturbaciones psíquicas graves). 
El Código Penal de la Nación Argentina (2013, Art. 34, inciso I), apunta que no es punible el que en el momento del hecho, ya sea por insuficiencia de sus facultades, por alteraciones morbosas de las mismas o por su estado de inconsciencia, error o ignorancia, no haya podido comprender la criminalidad del acto o dirigir sus acciones.

Por su parte, el Código Penal Alemán (1999, numeral 20) anota que actúa sin culpabilidad el que en la comisión del hecho por razón de un trastorno mental, de una consciencia alterada o por razón de deficiencia mental o de otras anomalías mentales graves, esté incapacitado para apreciar la injusticia del hecho o para actuar con esta intención, adicionando el artículo 21 que, si la capacidad del autor para apreciar la injusticia del hecho o para actuar con esta intención en el momento de comisión del hecho por las razones señaladas en el artículo 20 se ve notablemente reducida, la pena puede atenuarse.

Siguiendo la normativa alemana, en los últimos años ha tomado fuerza la idea de una fórmula cuatrimembre. Se afirma que la perturbación psíquica morbosa engloba los casos de las enfermedades mentales propiamente dichas; la perturbación profunda de la conciencia incluye alteraciones psíquicas tanto de base fisiológica (causadas por estados de sobre agotamiento, estados oníricos, etc.) como de naturaleza psicológica (estados hipnóticos, situaciones psíquicas inducidas por estados emotivos o pasionales de gran intensidad), integrando los llamados trastornos mentales transitorios. La tercera categoría, la oligofrenia, constituye una anomalía psíquica, identificable con el nombre de retraso mental. Por último, en la categoría de otras anomalías psíquicas graves, encuadran los supuestos de psicopatías y neurosis (Urruela Mora, 2004, pp. 213-214).

Hoy en día, la psicopatía es quizás el término que mayor discusión genera en relación con la inimputabilidad.

Al respecto, García Baamonde, Macarena Blázquez, Moreno Manso y Pozueco Romero (20I5, pp. 226227) señalan que las polémicas y confusiones que giran en torno al concepto de psicopatía son numerosas y proceden de diversos aspectos, tales como su evolución conceptual histórica, su frecuente asociación con conductas antisociales y delictivas, siendo que aunque el debate sigue abierto a nivel teórico, muchas investigaciones han venido subrayando de manera reiterada la necesidad de no encasillar a la psicopatía como un tipo de trastorno mental (ni de la personalidad ni de cualquier otra índole).

No obstante, tal y como lo anotan Agustina y Lorenzo (2016, p. 99), la relevancia práctica del estudio clínico y forense de la psicopatía y los trastornos de la personalidad se ha acentuado en los últimos años, en los que, asimismo, se ha generado un creciente interés por el estudio de la imputabilidad penal desde las neurociencias y su impacto en el Derecho penal. Sobre la base de los nuevos descubrimientos, se ha empezado a apuntar que, al menos en algunos casos, la psicopatía podría eliminar la imputabilidad en un futuro no demasiado lejano.

Hoy, resulta relevante entender, bajo las neurociencias, la psiquiatría y psicología contemporánea cuáles enfermedades mentales pueden ser comprendidas dentro de los presupuestos del legislador, quien utiliza los conceptos de manera amplia, abarcando las múltiples posibilidades que ofrece la ciencia (Leyton Jiménez, 2014, p. 42). 
A grosso modo, podría decirse que, actualmente, dentro de las enfermedades mentales se han incluido, entre otras, la esquizofrenia, la psicosis maniaco-depresiva y la demencia. Por su parte, se ha conceptualizado el desarrollo mental insuficiente (oligofrenias, estados de retraso mental, subnormalidad o deficiencia mental). Dentro de la grave perturbación de la conciencia se encuentran las intoxicaciones por consumo de alcohol, drogas, sustancias enervantes, estupefacientes u otras sustancias semejantes y los afectos o estados emocionales. Finalmente, con mayor discusión, una parte de la doctrina ha ubicado entre otras anomalías o alteraciones mentales, la psicopatía, la paidofilia y trastornos del control de los impulsos (Harbottle Quirós, 2012, pp. 52-139).

En cuanto a los trastornos mentales, existen múltiples categorizaciones que están en constante revisión. Castellano Arroyo, Gisbert Calabuig y Sánchez Blanque (2005, p. 1060) señalan que en la actualidad, existen dos clasificaciones a nivel internacional que poseen una mayor vigencia: la de la Organización Mundial de la Salud (Clasificación Internacional de las Enfermedades, CIE-10) y la de la Asociación Psiquiátrica Americana, con el Manual Diagnóstico y Estadístico de los Trastornos Mentales de la Asociación de Psiquiatría Americana (DSM).

Según se expone en un reciente Manual de Medicina Legal para Juristas, publicado por la Agencia Española de Cooperación Internacional para el Desarrollo y Procuraduría General de la República Dominicana (2016, p. 365), existen dos Clasificaciones Internacionales, una dependiente de la Organización Mundial de la Salud denominada CIE- 10 (su décima revisión), y otra dependiente de la Asociación de Psiquiatría Americana denominada DSM-5. Si bien los códigos y los términos de ambas son compatibles, con frecuencia en el ámbito judicial se observa como los peritos emplean la clasificación dependiente de la Asociación de Psiquiatría Americana DSM-5, pese a realizarse en Europa. La codificación permite aunar las nosologías, establecer los criterios para un determinado diagnóstico, el tratamiento adecuado y permite la comunicación adecuado entre los expertos y entre expertos y organismos gubernamentales y extragubernamentales (como la Organización Mundial de la Salud). No obstante, debe tenerse claro que el contar con un manual que describe qué criterios debe de cumplir un determinado trastorno no puede sustituir en ningún caso el criterio de un experto.

Indistintamente de la clasificación que se siga, lo cierto es que al estudiar los trastornos mentales, hay que tener presente que estos se deben a causas muy diversas, entre ellas, fundamentos biológicos, de personalidad, del ambiente, etc. Para identificarlas, se debe tomar en cuenta la interacción de todas las dimensiones relevantes: las contribuciones genéticas, la función del sistema nervioso, los procesos conductuales y cognoscitivos, las influencias emocionales, sociales e interpersonales y los factores del desarrollo (Durand y Barlow, 2007, p. 70).

Una vez presentado este recuento sobre las principales causas que pueden llegar a excluir o disminuir la capacidad de culpabilidad, se torna imperioso dar paso al análisis de sus componentes.

\section{Componentes de la capacidad de culpabilidad}

La doctrina especializada ha advertido que la imputabilidad se trata de un concepto jurídico de base psicológica en el que tradicionalmente se distingue entre un elemento biológico o psiquiátrico, cuya determinación corresponde según la jurisprudencia a los peritos, y un elemento psicológico-normativo, cuya determinación compete el juez (Demetrio Crespo, 2016, pp. 435-436). 
El concepto de capacidad de imputabilidad en el Derecho penal de adultos tiene dos niveles. El primero, es un componente empírico (fáctico) o biopsicológico. Debe verificarse si el sujeto tiene capacidad de culpabilidad con base en ciertos presupuestos de normalidad psíquica, utilizando un método y criterios psicológicos y psiquiátricos. Para ello, se requiere el diagnóstico psicológico o psiquiátrico forense sobre la existencia de estados psicopatológicos o anomalías psíquicas graves (enfermedades mentales) de carácter orgánico o de base biológica; trastornos cuya causa no es orgánica, corporal o biológica (como, por ejemplo, las psicopatías, las neurosis y ciertas anomalías de los instintos) y deficiencias o retrasos en el desarrollo de ciertas capacidades o funciones como las cognitivas. El segundo, es un componente normativo-valorativo. La determinación de si existe una enfermedad mental, un grave trastorno de la conciencia o un déficit en el desarrollo de ciertas capacidades cognitivas, es relevante en el tanto esos fenómenos influyen en la capacidad de comprensión y en la capacidad de acción, de voluntad y de inhibición de un sujeto respecto de un ilícito penal sancionado por el ordenamiento jurídico (Poder Judicial de Costa Rica, 20I I, Sala Tercera, Sentencia 20I I-00934).

De seguido se procede con la explicación de los dos componentes de la capacidad de culpabilidad.

\section{I. Empírico: labor del perito}

Según lo expone Zazzali (20I5, p. 5I), la función del perito consiste en establecer si el sujeto, mientras cometía un delito, manifestaba o no fallas psíquicas que pudieran significar falta de discernimiento. Serán imputables aquellos sujetos que han gozado de funcionamiento mental racional en el momento de cometer el delito.

Al respecto, Martínez Garay (2005, pp. 359-360) apunta que la formulación del diagnóstico corresponde al perito, como especialista en psiquiatría o en psicología, o, al menos, con una formación general en medicina legal, que siempre supone unos conocimientos técnicos más depurados que los que pueda tener el juez. Ese diagnóstico se efectuará con la metodología y los recursos propios de la psiquiatría o psicología clínicas. Pero el perito debe proporcionar al juez, además, una valoración de ese diagnóstico desde la perspectiva específicamente forense, que prepare el camino para la determinación de la imputabilidad: debe expresar su opinión sobre aquellas características psicológicas del trastorno que son además importantes para la valoración jurídica de la responsabilidad de quien ha actuado bajo sus efectos. De acuerdo con Carrasco Gómez y Maza Martín (2003, pp. 142- I43), el diagnóstico debe referirse a dos situaciones y momentos diferentes, uno actual y otro retrospectivo, "a posteriori", referente al momento de la acción, siendo que ambos pueden resultar distantes en el tiempo (meses e incluso años).

Podría suceder que una persona cometa un delito motivado patológicamente por un grave trastorno mental y al cabo de los meses, en el momento de ser explorado, o incluso en el momento de acudir al juicio oral, dicho trastorno puede haber remitido y hasta desaparecido.

El que generalmente se trate de diagnósticos retrospectivos tiene sin duda dificultades, por lo que no pueden obviarse las dudas que pueden quedar abiertas en muchos casos, así como, en otros, el que las conclusiones son tan sólo la enunciación de meras hipótesis acerca de cómo pudo encontrarse una persona ante unos hechos y qué es lo que en realidad puso ocurrir, constituyéndose en diagnósticos con una carga importante de subjetividad. 
Para elaborar este diagnóstico retrospectivo, es preciso recoger los recuerdos y vivencias de cuando ocurrieron los hechos, si existen déficits de memoria, si hubo ideación delirante, estados alucinatorios, si refiere consumo de alcohol u otras sustancias, datos cuya fiabilidad suele ser dudosa. Incluso, podría ocurrir que no resulte posible contrastar la información y que la conclusión sea precisamente esa, que no es posible determinar objetiva o científicamente si cuando ocurrieron los hechos se presentaron algunas de estas circunstancias psíquicas en la persona evaluada.

De acuerdo con Martínez Garay (2005, p. 308), el perito debe exponer en sus conclusiones si la persona procesada padece de algún trastorno mental y, en su caso, cuál, así como sus características (gravedad, duración), cómo y en qué medida ese trastorno afecta sus funciones psíquicas relevantes desde la perspectiva jurídico-penal y el grado en que estima que, a consecuencia de ese trastorno, se encontraba afectada la imputabilidad del sujeto en el momento de los hechos.

El peritaje puede llegar a suscitar controversias dentro del proceso judicial, sobretodo, ante la existencia de dictámenes contradictorios sobre la imputabilidad del inculpado, en los que distintos especialistas mantienen criterios diagnósticos diferentes, incluso antagónicos, sobre el estado de salud mental de aquel y su incidencia en la ejecución del delito. Podría ocurrir que en un caso concreto un perito concluya que al momento de los hechos la persona valorada tenía plena capacidad, que otro considere que del todo no la tenía e, incluso, que otro especialista estime que presentó una disminución en sus facultades.

En palabras simples: la valoración sobre la capacidad mental de una persona por sí misma es compleja. Presenta aún un mayor grado de dificultad en los casos en los que la persona acusada simula tener un trastorno o alteración psíquica.

El diagnóstico de la simulación requiere en la mayor parte de los casos una observación directa y lo más prolongada posible, siendo recomendable que el perito o no se forme un juicio prematuro en contra del procesado (Castellano Arroyo et al., 2005, p. 1060).

Al respecto, Inda Caro, Lemos Giráldez, López Rodrigo y Alonso Rionda (20I4, p. 90I), señalan que la simulación, el engaño o el fingimiento, potencialmente se pueden manifestar en todo tipo de enfermedades somáticas y trastornos mentales. Por eso es necesario utilizar también procedimientos de evaluación diferentes para desenmascarar a las personas que pudieran presentar o exagerar síntomas de muy diverso orden.

De ahí la importancia, como lo apunta Ackerman (2010, Pp. I-2I), de que el psicólogo forense esté entrenado en la aplicación e interpretación de distintos test para un mismo ámbito de evaluación (por ejemplo, personalidad, síntomas psicopatológicos, estilos educativos, etc.), rotando en la utilización de los mismos o aplicando varios en una misma sesión para validar la información obtenida.

El perito (psiquiatra o psicólogo forense) a la hora realizar el informe pericial debe contar principalmente con la entrevista realizada al examinado, sin embargo, también debe tener en cuenta otras evidencias para emitir sus conclusiones, como la lectura del expediente, la realización de exámenes para clínicos complementarios, la historia clínica, fotografías de la escena (primaria y secundaria), antecedentes disciplinarios y penales, informes escolares o de rendimiento laboral, etc (Rojas, 2013, pp. 5I-52). 
El dictamen pericial debe integrar los datos obtenidos con métodos diversos (la entrevista y los test específicos), así como contrastarlos con fuentes de información múltiples (entrevistas a familiares o análisis de la documentación obrante en el expediente judicial). Si hay discrepancias entre estas fuentes de información, la buena práctica requiere señalar las contradicciones detectadas en el informe final y planteárselo así al Tribunal. Actuar de forma contraria (excluir lo que resulta disonante e integrar en el informe sólo lo que es coherente con la hipótesis inicial del evaluador) supone una mala praxis y un falseamiento de la realidad de la evaluación psicológica.

Bajo este contexto, los peritos deben fundamentar los dictámenes científicos, especialmente en materias como la psicología y la psiquiatría, en las que los resultados de los exámenes no presentan el grado de exactitud que pueden tener algunas pruebas biológicas o químicas.

Conforme lo apunta Armaza Armaza (2013, p. 58), la labor del evaluador en el peritaje psicológico de la imputabilidad de una persona concreta pasa por tres momentos trascendentales:

I. La determinación de la presencia de un trastorno mental, su entidad, significación, evolución y, en su caso, pronóstico.

2. El análisis de la forma en la cual dicho trastorno altera la capacidad de conocer la ilicitud de sus acciones (capacidad cognitiva) o la capacidad de obrar conforme a dicho conocimiento (capacidad volitiva).

3. El establecimiento de la relación de causalidad entre el trastorno con los déficits de las capacidades asociadas, así como con la conducta típica y anti jurídica en cuestión.

Ahora bien, tal y como lo indica Ciófalo Zúñiga (1985, pp. 4-5), los peritos no son jueces sino auxiliares de la justicia, por tal motivo no deben sentenciar al proporcionar dictámenes de imputabilidad o inimputabilidad en los casos penales. No deben ejecutar funciones que competen única y exclusivamente a la autoridad judicial. A los peritos se les debe preguntar acerca del estado de las funciones anímicas, cuál de ellas está afectada y en qué grado, lo cual no significa que deban abstenerse de toda formación criminológica y jurídica, pero es ahí donde están las lagunas de su formación meramente psicológica.

En la jurisprudencia costarricense se ha dicho que el límite de la competencia de los peritos lo constituye la elaboración de un diagnóstico en el que se refiera a datos reales acerca de la existencia de enfermedades mentales o trastornos de la conciencia, considerándose que no les corresponde a los peritos forenses:

"emitir valoraciones acerca de la incidencia que tienen los anteriores supuestos sobre la capacidad de comprensión y sobre la capacidad de acción e inhibición de un sujeto en relación con el ilícito concreto por el cual está siendo juzgado; sencillamente porque este segundo componente o nivel del concepto es de carácter normativo-valorativo, lo cual significa que le compete exclusivamente al juzgador o la juzgadora del caso valorar los datos que le ofrecen los peritos, para concluir si aquello que fue diagnosticado por los expertos forenses ha tenido alguna incidencia relevante en la capacidad de comprensión y de acción (o inhibición) del sujeto actuante respecto del tipo penal concreto por el cual está siendo juzgado"(Poder Judicial de Costa Rica, 2013, Sala Tercera, Sentencia 20I300739). 
La afirmación o negación (determinación) de la imputabilidad de una persona dentro de un proceso penal es una labor que le corresponde al órgano jurisdiccional. Este es, precisamente, el tópico que se abordará de seguido.

\subsection{Normativo: labor del órgano juzgador}

De acuerdo con la mayoría de ordenamientos en el Derecho comparado, la declaratoria de inimputabilidad corresponde al juez del caso, mientras que los peritos psicólogos o psiquiatras prestan su colaboración, aportando su conocimiento científico especializado (Rojas, 20I3, PP. 50-5I).

Conforme lo establece Armanza Armanza (2013, p. 56), desde el plano de la Psiquiatría y Psicología Forense, algunos autores ponen de manifiesto la necesidad de la diferenciación entre las nociones de imputabilidad psíquica -cuya valoración le correspondería al psiquiatra o al psicólogo forense en vista de que son quienes poseen la capacitación adecuada para pronunciarse respecto de la relación de causalidad psíquica entre el inculpado y sus acciones- $y$, por otro lado, la de imputabilidad jurídica, concebida como aquel elemento (presupuesto) normativo de la culpabilidad y sobre la cual, únicamente, puede pronunciarse el Juez o el Tribunal.

La determinación de la capacidad de la persona sometida al proceso penal al momento de los hechos delictivos para comprender su carácter ilícito y de determinarse de acuerdo con esa comprensión, es una decisión netamente jurisdiccional. Si bien, es posible que un Tribunal decida sobre la imputabilidad o no de una persona sin contar con un dictamen pericial, es inobjetable el hecho de que una pericia elaborada bajo parámetros de validez y confiabilidad aporta información valiosa al juez o a la jueza en la toma de decisiones.

Para establecer la inimputabilidad del procesado, el juez puede valerse de varios elementos materiales probatorios y no sólo del informe pericial, principalmente la historia clínica del sujeto, documentos, entrevistas de amigos, familiares, compañeros, la víctima, etc (Rojas, 2013, p. 5I).

No cabe la menor duda de que las pericias constituyen una guía valiosa para el juez, siendo necesario que éste, por medio de un análisis detallado, proceda a determinar si con la sola presencia de una anomalía en el imputado se afectan las capacidades mentales de comprensión y determinación respecto de la ilicitud del comportamiento que realizó (Poder Judicial de Costa Rica, 2009, Sala Tercera, Sentencia 2009-00444).

Si bien, los dictámenes periciales no vinculan a quien juzga, para separarse de ellos deben exponerse razones de naturaleza técnica, ajustadas a las reglas de la sana crítica, en todos aquellos casos en que el juzgador no tenga conocimientos especializados y requiera del auxilio de peritos, como ocurre con la psiquiatría y la psicología. Si el Tribunal tiene dudas sobre la conclusión pericial, lo ideal es que ordene la ampliación de los dictámenes, o que solicite se hagan otros con nuevos peritos, o que estos concurran al juicio para evacuar todas las dudas que al respecto surjan.

Cuando el dictamen del perito está debidamente fundado y demuestra un desarrollo lógico y coherente en relación con otros elementos de prueba, resulta más difícil para los jueces apartarse de sus conclusiones. 
Finalmente, debe indicarse que, tal y como lo explican López Miguel y Núñez Gaitán (2014, p. 885), para poder aplicar una eximente de culpabilidad debe valorarse la naturaleza de la perturbación (criterio cualitativo), la intensidad o grado de la perturbación (criterio cuantitativo), la duración del trastorno y permanencia del mismo (criterio cronológico) y la relación de causalidad o de sentido entre el trastorno mental y el hecho delictivo (criterio de causalidad).

\section{Conclusiones}

En el siglo XIX se dio una importante discusión sobre la categoría dogmática denominada capacidad de culpabilidad o imputabilidad, así como sobre la inimputabilidad e imputabilidad disminuida, las cuales se llegaron a concebir de forma distinta por la Escuela Clásica y la Escuela Positivista.

Hoy, a raíz de diversos descubrimientos de las neurociencias, se ha activado el debate sobre libertad vs determinismo. Ante ciertos trastornos mentales, ies posible pensar en que el sujeto actúa de forma libre?, bajo esas condiciones, deben replantearse las respuestas que ofrece actualmente el Derecho penal? Sin duda alguna este tema tiene relación directa con la capacidad de culpabilidad.

La imputabilidad es un concepto complejo. Tiene dos niveles o dimensiones: el componente empírico o biopsicológico (diagnóstico psicológico o psiquiátrico forense sobre la existencia de estados psicopatológicos o anomalías psíquicas) y el componente normativo-valorativo (determinación jurisdiccional de si dichos estados o anomalías tuvieron incidencia en la capacidad cognoscitiva o volitiva del acusado al momento del hecho delictivo).

Si bien, existen enfermedades mentales como la esquizofrenia y la psicosis maniaco-depresiva, así como retrasos mentales, que sin duda alguna inciden en la capacidad de culpabilidad de una persona, dadas las múltiples clasificaciones mundiales y los constantes cambios, actualmente no es viable pensar en una lista taxativa de causas de inimputabilidad o imputabilidad disminuida. Anomalías o alteraciones mentales relacionadas con el control de los impulsos sobre las que no existe consenso deben ser estudiadas con mayor profundidad.

En la praxis judicial, los dictámenes periciales tienen gran influencia en la toma de decisiones del juzgador a efectos de concluir sobre el estado mental de la persona acusada en el momento de la comisión de un delito. No obstante, dentro del proceso judicial es perfectamente factible que el peritaje suscite discusiones, al estarse frente a una materia que no admite criterios exactos de determinación.

El órgano juzgador es "perito de peritos" y quien a fin de cuentas tiene la última palabra en cuanto a la capacidad de culpabilidad de la persona acusada.

Ante un tema que rebasa los conocimientos legales, resulta incuestionable la necesidad de que se dé un mayor acercamiento y una mejor comunicación entre jueces y peritos, que permita una interrelación entre lo pericial y lo legal.

Es indispensable que los peritos cuenten con los instrumentos idóneos y la preparación profesional adecuada para emitir los dictámenes y que los jueces tengan mayor conocimiento en psicología y psiquiatría forense. 
Se finaliza este artículo parafraseando a Cabello (198I, pp. 73-74), quien hace varias décadas resumió de manera muy clara la idea que se pretende dejar al lector: los juzgadores no deben únicamente homologar el informe, pues ellos son los que deben establecer la culpabilidad del agente; tampoco deben subestimarlo porque no se acomode a su manera de pensar; no han de rebatir en el mismo plano cuestiones que son del dominio exclusivo del especialista; no deben quedarse con la duda, por lo que el nombramiento de nuevos peritos, con exclusión de los que dictaminaron anteriormente, e incluso apelando a los oficiales, son recursos suficientes para que pondere las diferentes opiniones a efectos de formar su propio juicio; las conclusiones de las pericias no los obligan; de lo contrario, importaría delegación de justicia. No obstante, tampoco deben apartarse de sus conclusiones sin llevar a cabo una debida fundamentación, pues tienen que resolver conforme a la sana crítica y los principios científicos.

\section{Bibliografía}

Ackerman, M. J. (20I0). Introduction to essentials of forensic assessment. En A. S. Kaufman \& N. L. Kaufman (Eds.), Essentials of Forensic Psychological Assessment (pp. I-2I). New Jersey, EEUU: John Wiley \& Sons.

Agencia Española de Cooperación Internacional para el Desarrollo y Procuraduría General de la República Dominicana. (2016). Manual de Medicina Legal para Juristas. Santo Domingo. Recuperado de http://www.aecid.org.do/images/noticias/Noticias/I3_06_20I6/DOC-20160609-WA0004.pdf.

Agustina, J. y Lorenzo, F. (2016). Sobre el confuso concepto de psicopatía en la jurisprudencia del Tribunal Supremo español: una revisión crítica ante los nuevos retos del Derecho penal de la peligrosidad. Revista Política Criminal, II (2I), 66-103. Recuperado de http://www.scielo.cl/pdf/politcrim/vI In2 I/art04.pdf.

Armaza Armaza, E. (2013). El Tratamiento Penal del Delincuente Imputable Peligroso. Granada, España: Editorial Comares.

Arocena, G., Balcarce, F. y Cesano, J. (20I5). Derecho penal y neurociencias. Buenos Aires, Argentina: Hammurabi.

Carrasco Gómez, J. y Maza Martín, J. (2003). Manual de Psiquiatría Legal y Forense. Madrid, España: La Ley.

Casanueva Sanz, I. (2013). Una revisión del concepto de imputabilidad desde las ciencias de salud. Su compatibilidad con la regulación penal vigente. Revista de Estudios de Deusto, 62(I), I5-46. Recuperado de http://revista-estudios.revistas.deusto.es/article/view/232/362.

Castellano Arroyo, M, Gisbert Calabuig, J. y Sánchez Blanque, A. (2005). Medicina Legal y Toxicología. Barcelona, España: Editorial Masson.

Cabello, V. (198I). Psiquiatría forense en el derecho penal, Vol. I. Buenos Aires, Argentina: Hammurabi. Chan Mora, G. (20I2). La Culpabilidad Penal. San José, Costa Rica: Investigaciones Jurídicas S.A.

Ciófalo Zúñiga, F. (1985). Del dictamen en materia psiquiátrica o psicológica forenses. Revista de Medicina Legal de Costa Rica, 3 (2), 4-5. 
Código Penal de Costa Rica (2015). San José, Costa Rica: Investigaciones Jurídicas S.A.

Código Procesal Penal de Costa Rica (20/3). San José, Costa Rica: Investigaciones Jurídicas S.A.

Código Penal de España y legislación complementaria (20I5). Madrid, España: Agencia Estatal Boletín Oficial del Estado.

Código Penal de la Nación Argentina (2013). La Plata-Buenos Aires, Argentina: Editorial Lex.

Código Penal Alemán (1999). En C. López Díaz (traductora), Traducción del Strafgesetzbuch (1998). Bogotá, Colombia: Universidad Externado de Colombia. Recuperado de http://perso.unifr.ch/derechopenal/assets/files/legislacion/l_20080616_02.pdf.

Corcoy Bidasolo, M. y Mir Puig, S. (2015). Comentarios al Código Penal. Valencia: Tirant lo blanch.

Demetrio Crespo, E. (2016). La Culpabilidad. Elementos de la culpabilidad. La imputabilidad. En: Lecciones de Derecho Penal. Teoría del Delito, Tomo II (pp. 435-472). San José, Costa Rica: Editorial Jurídica Continental.

Demetrio Crespo, E. (2015). Libertad de Voluntad, Investigación sobre el Cerebro y Responsabilidad Penal. Aproximación a los Fundamentos del Moderno Debate sobre Neurociencias y Derecho Penal. Revista Digital de la Maestría en Ciencias Penales, (7), I-52. Recuperado de http://revistas.ucr.ac.cr/index.php/RDMCP/article/view/I2439/II693.

Durand, M. y Barlow, D. (2007). Psicopatología. Un enfoque integral de la psicología anormal, México: Cengage Learning.

García Baamonde, M., Macarena Blázquez, A., Moreno Manso, J. y Pozueco Romero, J. (2015). Psicopatía y psicopatologías: ¿Puede conceptualizarse la psicopatía como trastorno mental? Revista de Psicopatología y Psicología Clínica, (20), 219-230. Recuperado de http://revistas.uned.es/index.php/RPPC/article/view/I5897/pdf_64.

Harbottle Quirós, F. (20I2). Imputabilidad Disminuida. Hacia una redefinición de la imputabilidad e inimputabilidad. San José, Costa Rica: Editorial Juritexto.

Inda Caro, M, Lemos Giráldez, S., López Rodrigo, A. y Alonso Rionda, J. (2014). La Simulación de Enfermedad Física o Trastorno Mental. En Pozueco Romero, J (Coord.), Tratado de Psicopatología Criminal. Psicología Jurídica y Psiquiatría Forense, Vol. II (pp. 89I-905). Madrid, España: Editorial EOS.

Leyton Jiménez, J. (20I4). El concepto de imputabilidad disminuida a la luz del principio de culpabilidad y del conocimiento contemporáneo de las enfermedades mentales. Revista jurídica del Ministerio

(58), 9-46.

Recuperado dewww.fiscaliadechile.cl/Fiscalia/archivo?id=|727| \&pid=|64\&tid=|\&d=| .

Lin Ching, R. (2002). Psicología Forense: principios fundamentales. San José, Costa Rica: Euned. 
López Miguel, M. y Núñez Gaitán, M. (20 I4). Psicopatología y Delincuencia: Implicaciones en el Concepto de Imputabilidad. En Pozueco Romero, J (Coord.), Tratado de Psicopatología Criminal. Psicología Jurídica y Psiquiatría Forense, Vol. II (pp. 88I-890).Madrid, España: Editorial EOS.

Martínez Garay, L. (2005). La Imputabilidad Penal: Concepto, Fundamento, Naturaleza Jurídica y Elementos. Valencia, España: Tirant lo Blanch.

Muñoz Conde, F. (1988). La imputabilidad desde el punto de vista médico y jurídico penal. Derecho Penal y Criminología, 10 (35), 27-38.

Poder Judicial de Costa Rica. Corte Suprema de Justicia, Sala Tercera, Sentencia 2013-00739, del I4 de junio de 2013.

Poder Judicial de Costa Rica. Corte Suprema de Justicia, Sala Tercera, Sentencia 20I I-00934, del 29 de julio de $20 \mathrm{II}$.

Poder Judicial de Costa Rica. Corte Suprema de Justicia, Sala Tercera, Sentencia 2010-00957, del 14 de setiembre de 2010 .

Poder Judicial de Costa Rica. Corte Suprema de Justicia, Sala Tercera, Sentencia 2009-00444, del 31 de marzo de 2009.

Puig Peña, F. (1955). Derecho Penal. Parte General, Vol. Il. Madrid, España: Editorial Revista de Derecho Privado.

Rojas Salas, J.M. (2013). La inimputabilidad y el tratamiento del disminuido psíquico en el proceso penal. Revista de Derecho Penal y Criminología, 34 (97), 43-64. Recuperado de http://revistas.uexternado.edu.co/index.php/derpen/article/view/3868.

Roxin, C. (1997). Derecho Penal. Parte General. Fundamentos. La Estructura de la Teoría del Delito. Madrid, España: Cívitas.

Saborío Valverde, C. (2005). Estrategias de Evaluación Psicológica en el Ámbito Forense. Revista de Medicina Legal de Costa Rica, I, 4I-63. Recuperado de http://www.scielo.sa.cr/scielo.php?pid=SI 409$00152005000100004 \&$ script $=$ sci_arttext.

Soler, S. (1989): Derecho Penal Argentino. Buenos Aires, Argentina: Tipografía Editora Argentina.

Urruela Mora, A. (2004). Imputabilidad penal y anomalía o alteración psíquica. Granada, España: Editorial Comares.

Vela Treviño, S. (1988). La imputabilidad disminuida. Revista Criminalia, (I-I2), 293-32I.

Velásquez, F. (1997). Derecho Penal. Parte General. Bogotá, Colombia: Temis. 
Yáñez Román, P. (1970). Consideraciones en torno a la imputabilidad disminuida con especial referencia a los psicópatas. Su tratamiento y los denominados establecimientos de terapéutica social. Anuario de Derecho Penal y Ciencias Penales, (23), 30 I-390.

Zaffaroni, E. (2002). Derecho Penal, Parte General. Buenos Aires, Argentina: Ediar.

Zazzali, J. (20I5). Psiquiatría Forense. Buenos Aires, Argentina: Ediciones La Rocca. 